\title{
Functional movement screen evaluation system for the prevention of military training injuries: a prospective study in China
}

\section{Jing Zeng}

PLA Rocket Force University of Engineering

\section{Rong-Bing Zhang}

PLA Rocket Force University of Engineering

\section{Wei Wang}

PLA Rocket Force University of Engineering

Jing-Jiu Ke

PLA Rocket Force University of Engineering

\section{Xiang Wu}

PLA Rocket Force University of Engineering

\section{Li-Hua Chen}

PLA Rocket Force University of Engineering

Jun Xiao ( $\nabla 1772084889 @ q q . c o m$ )

Aerojet Rocketdyne

\section{Research}

Keywords: FMS, military training injuries, prevention, effectiveness, feasibility

Posted Date: April 14th, 2021

DOI: https://doi.org/10.21203/rs.3.rs-418344/v1

License: (c) (1) This work is licensed under a Creative Commons Attribution 4.0 International License. Read Full License 


\section{Abstract}

Background: Military training injury is a difficult problem in the field of military training. This study aimed to evaluate the effectiveness and feasibility of functional movement screen (FMS) evaluation system and individualized intervention measures in preventing military training injuries.

Methods: A total of 420 recruits from a unit of the People's Liberation Army of China (PLA) were included as the research object. According to random grouping method, they were divided into observation group (Group A) and control group (Group B) , with 210 patients in each group. Before recruit training, individual FMS were performed, and functional correction training was performed in the observation group according to the test scores, while no intervention measures were applied in the control group. After three months of training, the tests were repeated. Age, body mass index (BMI) and incidence of military training injuries were recorded during the training period.

Results: There was no statistical difference between the two groups in age, BMI, FMS score before the training $(P>0.05)$. After receiving functional correction training, the FMS score of the Group A was higher than that of the Group $B$, and the difference was statistically significant $(P<0.05)$. The incidence of military training injury in Group A and Group B was $20.95 \%$ and $44.02 \%$, respectively $(P<0.05)$, and the difference was statistically significant.

Conclusion: The evaluation system of FMS and individualized intervention measures are feasible and effective in predicting and reducing the occurrence of military training injuries.

\section{Background}

Military training is the fundamental way to improve the combat effectiveness of troops. Due to various reasons, the current military training injuries increase year by year and remain high [1]. According to literature, the incidence of training injuries in the UK is $48.6 \%[2], 23.2 \%$ in Norway [3], 21.0\% in the PLA [1], and $45.0 \%$ in the U.S. Marines [4].Therefore, countries around the world attach great importance to how to reduce military training injuries and carry out a series of studies [5-8], however, most have proved ineffective. The main reasons are the generality of the intervention measures and the lack of pertinence.Second, some risk factors for training injuries (smoking, age, BMI, etc.) are mostly individual characteristics, which are difficult to change.

Studies have pointed out that part of the reasons for military training injuries are the reduced flexibility of the trainees' joints and the asymmetry of muscle strength [9]. FMS was designed by Garry Cook to evaluate the quality and asymmetry of movement. It can effectively screen out the dysfunction and asymmetry of subjects during movement and has the ability to identify injury risk $[10,11]$. FMS has been widely used in rehabilitation training and physical training in competitive sports [12-14], nevertheless, studies on its application in the military field are relatively few. In this study, FMS test was conducted on recruits before military training, and personalized intervention and correction training was conducted 
according to the scoring results, so as to explore the effectiveness and feasibility of FMS evaluation system in predicting and reducing the occurrence of military training injuries.

\section{Methods}

\section{Study population}

This study is a prospective study design, including 420 recruits of PLA as the research object. According to the random grouping method, they were divided into the observation group (Group A) and the control group (Group B), with 210 members in each group. All the recruits were male. The mean age of the Group A was $19.8 \pm 1.5$ years and BMI was $22.3 \pm 2.9$ years.the mean age of the Group B was $19.7 \pm 1.4$ years and $\mathrm{BMI}$ was $22.3 \pm 2.8$ years. All subjects were strictly screened according to inclusion criteria and exclusion criteria, and obtained informed consent.

\section{Inclusion criteria and exclusion criteria}

Inclusion criteria: 1 . The research subjects have good compliance and can actively cooperate to complete various tests; 2.The subject has not received formal military training or other competitive training before.exclusion criteria: 1 . Subjects have medical history of neck, shoulder, waist, knee and other diseases;2. Those who cannot complete the FMS test due to various reasons is excluded.

\section{Study methods}

Standard FMS suites are applied. The test method follows the international standard working procedure of FMS. Orthopaedic surgeons, sports researchers and rehabilitation therapists were involved and all underwent a one-week training in FMS testing to ensure accuracy and reliability. The FMS test was performed in a relaxed state to eliminate the effects of fatigue. All subjects were tested twice by a professional and the average value is obtained. Seven tests (deep squats, hurdle step, inline lunge, shoulder flexibility, active straight- leg raise, trunk stability pushup, rotary stability) and three clearing exams were included in the FMS. We use a clearing exam at the first of the FMS. Each test is scored between 0 and 3, with an overall score of 0 to 21. According to the test results, the Group A was given corrective training, while the Group B was not given any intervention factors. After that, both groups received a 90-day military training according to the PLA military training program. The types of military training injuries that occurred to all subjects were recorded during this period.The FMS scores of all subjects were measured again after the training. Military training injury is defined as the injury of bone, soft tissue or organ in the process of military training, resulting in dysfunction affecting the normal military training for more than 1 day.

\section{Statistical analysis}

All data analysis was performed using SPSS version 25 (SPSS, Inc., Chicago, IL, USA) software. Data are expressed as the means \pm standard deviation for parametric samples,paired sample $t$ test was used for intra-group comparison, and independent sample t test was used for inter-group comparison. Chi-square 
test and Fisher's exact probability method were used for counting data of disordered classification. Univariate analysis was used to determine the correlation between the occurrence of training injury and $\mathrm{BMI}$ and FMS scores. $\mathrm{P}<0.05$ was considered statistically significant for all comparisons.

\section{Results}

\section{Recruits' demographics}

During the study period, FMS was performed on 420 recruits, of whom 17 were excluded. The remaining 403 recruits were included in the final analysis $\otimes F i g .1 \rrbracket$. These two groups had similar baseline demographic data $₫$ Table 1).

Table 1 Demographic data of the recruits

\begin{tabular}{|llll|}
\hline Variable & Group A & Group B & P value \\
\hline Age(year) & $19.8 \pm 1.5$ & $19.7 \pm 1.4$ & 0.15 \\
\hline BMI & $22.3 \pm 2.9$ & $22.3 \pm 2.8$ & 0.23 \\
\hline FMS score & $14.3 \pm 3.1$ & $14.2 \pm 3.0$ & 0.56 \\
\hline
\end{tabular}

\section{Training injuries and FMS scores}

Military training injury occurred in 44 recruits in the Group A and 92 recruits in the Group B $(21.89 \%$ and $45.54 \%$, respectively). The incidence of training injury in Group A was lower than that in Group $B$, and the difference was statistically significant $(P<0.05) \llbracket T a b l e 2 \rrbracket$.

Table 2 Occurrence of training injury in two groups of recruits

\begin{tabular}{|c|c|c|c|c|}
\hline Item & Injuries (n,\%) & No injuries $(n, \%)$ & $x^{2}$ value & $P$ value \\
\hline Group A & 44(21.89) & $157(78.11)$ & 9.28 & 0.02 \\
\hline Group B & $92(45.54)$ & 110ه54.46》 & & \\
\hline
\end{tabular}

At the end of the training, the FMS score of the Group A increased from $14.61 \pm 2.11$ to $16.23 \pm 2.09$ after the intervention of FMS correction strategy.The FMS score of the Group B increased from $14.59 \pm 2.09$ to $15.03 \pm 2.09$. The difference was statistically significant(Table 3 .

The final FMS score of the Group A was higher than that of the Group B, and the difference was statistically significant (Table 3).

Table 3 FMS score results for all recruits 


\begin{tabular}{|c|c|c|c|c|c|c|c|}
\hline \multirow[t]{2}{*}{ Variables } & \multicolumn{4}{|l|}{ Group A } & \multicolumn{2}{|l|}{ Group B } & \multirow[t]{2}{*}{$\# P$} \\
\hline & $\begin{array}{l}\text { Pre- } \\
\text { trainning }\end{array}$ & $\begin{array}{l}\text { Post- } \\
\text { trainning }\end{array}$ & ${ }^{*} \mathrm{P}$ & $\begin{array}{l}\text { Pre- } \\
\text { trainning }\end{array}$ & $\begin{array}{l}\text { Post- } \\
\text { trainning }\end{array}$ & ${ }^{*} \mathrm{P}$ & \\
\hline Deep squat & $2.31 \pm 0.61$ & $2.48 \pm 0.52$ & 0.03 & $2.29 \pm 0.56$ & $2.47 \pm 0.47$ & 0.12 & 0.49 \\
\hline Hurdle step & $1.99 \pm 0.57$ & $2.19 \pm 0.56$ & 0.01 & $2.00 \pm 0.53$ & $2.02 \pm 0.49$ & 0.09 & 0.13 \\
\hline In-line lunge & $1.92 \pm 0.75$ & $2.23 \pm 0.45$ & 0.01 & $1.91 \pm 0.78$ & $2.02 \pm 0.39$ & 0.03 & 0.01 \\
\hline $\begin{array}{l}\text { Shoulder } \\
\text { mobility }\end{array}$ & $1.96 \pm 0.53$ & $2.31 \pm 0.49$ & 0.01 & $1.95 \pm 0.54$ & $2.00 \pm 0.49$ & 0.07 & 0.01 \\
\hline $\begin{array}{l}\text { Active } \\
\text { straight- leg } \\
\text { raise }\end{array}$ & $2.52 \pm 0.34$ & $2.61 \pm 0.36$ & 0.05 & $2.53 \pm 0.43$ & $2.61 \pm 0.39$ & 0.21 & 0.46 \\
\hline $\begin{array}{l}\text { Trunk } \\
\text { stability } \\
\text { push-up }\end{array}$ & $2.02 \pm 0.92$ & $2.23 \pm 0.62$ & 0.03 & $2.01 \pm 0.89$ & $2.12 \pm 0.59$ & 0.02 & 0.03 \\
\hline $\begin{array}{l}\text { Rotatory } \\
\text { stability }\end{array}$ & $1.92 \pm 0.61$ & $2.12 \pm 0.23$ & 0.02 & $1.90 \pm 0.59$ & $1.95 \pm 0.23$ & 0.11 & 0.04 \\
\hline FMS scores & $14.61 \pm 2.11$ & $16.23 \pm 2.09$ & 0.01 & $14.59 \pm 2.09$ & $15.03 \pm 2.09$ & 0.02 & 0.04 \\
\hline
\end{tabular}

*P, Compared within groups; \#P, compared among groups

\section{Correlation analysis of training injury and FMS score}

We further analyzed the correlation between different FMS scores and BMI values and the occurrence of training injuries, suggested that FMS score and BMI were correlated with the occurrence of training injury $(P<0.05)($ Table 4). The results showed that FMS score and BMI were the risk factors of training injury.

Table 4 Univariate analysis of training injury and BMI and FMS scores 


\begin{tabular}{|c|c|c|c|c|c|}
\hline \multicolumn{2}{|l|}{ Variables } & Injuries & No injuries & $x^{2}$ & P \\
\hline & $\leq 12$ & 32 & 41 & 8.96 & 0.01 \\
\hline \multirow[t]{3}{*}{ FMS score } & $12 \bigotimes 14$ & 56 & 80 & & \\
\hline & $\geq 14$ & 48 & 146 & & \\
\hline & $\leq 18.5$ & 4 & 8 & 13.12 & 0.04 \\
\hline \multirow[t]{2}{*}{ BMI } & $18.5 \llbracket 25$ & 89 & 210 & & \\
\hline & $\geq 25$ & 43 & 49 & & \\
\hline
\end{tabular}

\section{Discussion}

Military training injuries restrict the improvement of military combat effectiveness and increase a large number of unnecessary expenses [15]. At present, the armies of all countries in the world attach great importance to the occurrence of training injuries, and have carried out a series of related studies [5-8]. However, most studies were limited to training history, injury history, smoking, age, gender, and BMI, These risk factors for injury are mostly individual characteristics that are often difficult to change. FMS can effectively screen out the dysfunction and asymmetry of subjects during movement $[10,11]$, therefore, targeted intervention can theoretically reduce the occurrence of training injury.

The incidence of military training injuries is a key indicator to evaluate the effectiveness of intervention measures, Coppack [16] and Sharma [17] pointed out that effective intervention measures for training injuries should be targeted at specific injury mechanisms. In the study, there was no statistical difference in the FMS score between the two groups before training. After training, the FMS score of the Group A was $16.23 \pm 2.09$, which was higher than that of the Group B $15.03 \pm 2.09(P<0.05)$. The incidence of military training injury in the Group A was $20.95 \%$ lower than that of the Group B $(44.02 \%, P<0.05)$. It indicated that FMS intervention is effective to improve the FMS score and reduce the incidence of training injury. Bushman et al. [11] pointed out that FMS score could be a risk factor for the occurrence of military training injuries, and the establishment of FMS archives for recruits preparing for military training could provide information for the future risk management strategies of this population.

It has been reported in previous literature [18-20] that when FMS score is lower than 14 points, the potential probability of training injury will increase.O'Connor [18] found that when the FMS score of trainees was lower than 14, the probability of training injury increased by 1.91 times. Brushoj et al. [21] also pointed out that when the flexibility of the body is reduced and the muscle strength is asymmetrical, rough military training is difficult to change the mobility and stability of the body without increasing the 
compensation of the body and the probability of injury. In this study, by comparing and analyzing the occurrence of training injuries with different FMS scores, the correlation between FMS scores and the occurrence of military training injuries was further confirmed ( Table 4), which is consistent with the views of the above-mentioned scholars. Therefore, it is feasible to predict the occurrence of military training injury based on FMS evaluation system.

Another finding of the study was that 209 recruits (51.86\%) (Table 5) had FMS scores below the 14 cutoff point, which is worrisome and implies that these recruits have a potentially higher incidence of military training injuries. Bock et al. [22] pointed out in their study that FMS scores are related to the performance of tactical crowd on tasks, and police officers with lower FMS scores perform worse in defensive tactical tasks.Stanek[23] pointed out that firefighters require to practice a variety of functional movements, which can lead to a safer and more effective performance. Therefore, based on the current research results, it is necessary to actively carry out FMS testing and timely targeted intervention in the process of military training.

Although our study has reached some conclusions, there are the following limitations.Firstly, restricted by the training conditions, it is difficult for the subjects to ensure the homogeneity in training intensity and training time. Secondly, a prospective study design might have recorded a higher incidence of training injuries due to increased awareness of injury in the control subjects.At last, The individual intervention measures of FMS and the effectiveness of the system in preventing military training injuries still need to be demonstrated with large sample.

\section{Conclusions}

Based on the findings, the evaluation system based on FMS is feasible in predicting the occurrence of military training injuries, and targeted intervention measures can significantly reduce the occurrence of military training injuries.

\section{Declarations}

\section{Acknowledgments}

The authors express their gratitude to all members of the department for their assistance.

\section{Authors' contributions}

$\mathrm{JX}$ and $\mathrm{JZ}$ conducted the experiments and wrote the manuscript, RBZ, JJK, XW,WW and LHC collected and analyzed the data. RBZ supervised the project. All authors read and approved the final manuscript.

\section{Funding}

This work was supported by the PLA Military Special plan for innovation and generation of military health

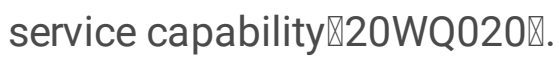


Availability of data and materials

The datasets used and/or analysed during the current study are available from the corresponding author on reasonable request.

\section{Ethics approval and consent to participate}

This trial was approved by the Guangzhou Special Service Recuperation Center of PLA Rocket Force Biomedical Research Ethics Committee. Informed consent was obtained from all participants.

\section{Consent for publication}

Informed consent for publication was obtained from all participants.

\section{Competing interests}

All authors declare no conflicts of interest.

\section{Authors' information}

Full list of author information is available at the first of the article

\section{Abbreviations}

BMI: Body mass index; FMS: Functional movement screen $₫$ PLA囚People's liberation army

\section{References}

1. Hua W, Chen Q, Wan M, Lu J, Xiong L. The incidence of military training-related injuries in Chinese new recruits: a systematic review and meta-analysis. J R Army Med Corps. 2018;164(4):309-13.

2. Sharma J, Greeves JP, Byers M, Bennett AN, Spears IR. Musculoskeletal injuries in British Army recruits: a prospective study of diagnosis-specific incidence and rehabilitation times. BMC Musculoskelet Disord. 2015;16:106.

3. Heir T, Glomsaker P. Epidemiology of musculoskeletal injuries among Norwegian conscripts undergoing basic military training. Scand J Med Sci Sports. 1996;6(3):186-91.

4. Teyhen DS, Shaffer SW, Butler RJ, Goffar SL, Kiesel KB, Rhon DI, Williamson JN, Plisky PJ. What Risk Factors Are Associated With Musculoskeletal Injury in US Army Rangers? A Prospective Prognostic Study. Clin Orthop Relat Res. 2015;473(9):2948-58.

5. Cowan DN, Bedno SA, Urban N, Yi B, Niebuhr DW. Musculoskeletal injuries among overweight army trainees: incidence and health care utilization. Occup Med (Lond). 2011;61(4):247-52.

6. Kaufman KR, Brodine S, Shaffer R. Military training-related injuries: surveillance, research, and prevention. Am J Prev Med. 2000;18(3 Suppl):54-63. 
7. Jones BH, Cowan DN, Tomlinson JP, Robinson JR, Polly DW, Frykman PN. Epidemiology of injuries associated with physical training among young men in the army. Med Sci Sports Exerc. 1993;25(2):197-203.

8. Finestone A, Milgrom C, Evans R, Yanovich R, Constantini N, Moran DS. Overuse injuries in female infantry recruits during low-intensity basic training. Med Sci Sports Exerc. 2008;40(11 Suppl):630-5.

9. Hauschild VD, Lee T, Barnes S, Forrest L, Hauret K, Jones BH. The Etiology of Injuries in US Army Initial Entry Training. US Army Med Dep J. 2018(2-18):22-29.

10. Bonazza NA, Smuin D, Onks CA, Silvis ML, Dhawan A. Reliability, Validity, and Injury Predictive Value of the Functional Movement Screen: A Systematic Review and Meta-analysis. Am J Sports Med. 2017;45(3):725-32.

11. Bushman TT, Grier TL, Canham-Chervak M, Anderson MK, North WJ, Jones BH. The Functional Movement Screen and Injury Risk: Association and Predictive Value in Active Men. Am J Sports Med. 2016;44(2):297-304.

12. Jones SC, Fuller JT, Chalmers S, Debenedictis TA, Zacharia A, Tarca B, et al. Combining physical performance and Functional Movement Screen testing to identify elite junior Australian Football athletes at risk of injury. Scand J Med Sci Sports. 2020;30(8):1449-56.

13. Hoover DL, Killian CB, Tinius RA, Bellar DM, Wilkinson SG, Esslinger FT, et al. Predictive Validity of a Functional Movement Screen in Professional Basketball Players. Medicina (Kaunas). 2020; 56(12).

14. Miyamori T, Nagao M, Shimasaki Y, Okazaki T, Akiyoshi N, Nishio H, et al. Reliability assessment of the functional movement screen for predicting injury risk in Japanese college soccer players. J Phys Ther Sci. 2020;32(12):850-5.

15. Lovalekar M, Johnson CD, Eagle S, Wohleber MF, Keenan KA, Beals K, et al. Epidemiology of musculoskeletal injuries among US Air Force Special Tactics Operators: an economic cost perspective. BMJ Open Sport Exerc Med. 2018;4(1):e000471.

16. Coppack RJ, Etherington J, Wills AK. The effects of exercise for the prevention of overuse anterior knee pain: a randomized controlled trial. Am J Sports Med. 2011;39(5):940-8.

17. Sharma J, Weston M, Batterham AM, Spears IR. Gait retraining and incidence of medial tibial stress syndrome in army recruits. Med Sci Sports Exerc. 2014;46(9):1684-92.

18. O'Connor FG, Deuster PA, Davis J, Pappas CG, Knapik JJ. Functional movement screening: predicting injuries in officer candidates. Med Sci Sports Exerc. 2011;43(12):2224-30.

19. Kiesel K, Plisky PJ, Voight ML. Can Serious Injury in Professional Football be Predicted by a Preseason Functional Movement Screen? N Am J Sports Phys Ther. 2007;2(3):147-58.

20. Everard E, Lyons M, Harrison AJ. Examining the association of injury with the Functional Movement Screen and Landing Error Scoring System in military recruits undergoing 16 weeks of introductory fitness training. J Sci Med Sport. 2018;21(6):569-73.

21. Brushoj C, Larsen K, Albrecht-Beste E, Nielsen MB, Loye F, Holmich P. Prevention of overuse injuries by a concurrent exercise program in subjects exposed to an increase in training load: a randomized controlled trial of 1020 army recruits. Am J Sports Med. 2008;36(4):663-70. 
22. Bock C, Stierli M, Hinton B, Orr R. The Functional Movement Screen as a predictor of police recruit occupational task performance. J Bodyw Mov Ther. 2016;20(2):310-5.

23. Stanek JM, Dodd DJ, Kelly AR, Wolfe AM, Swenson RA. Active duty firefighters can improve Functional Movement Screen (FMS) scores following an 8-week individualized client workout program. Work. 2017;56(2):213-20.

\section{Table 5}

Table 5 was not provided with this version of the manuscript.

\section{Figures}

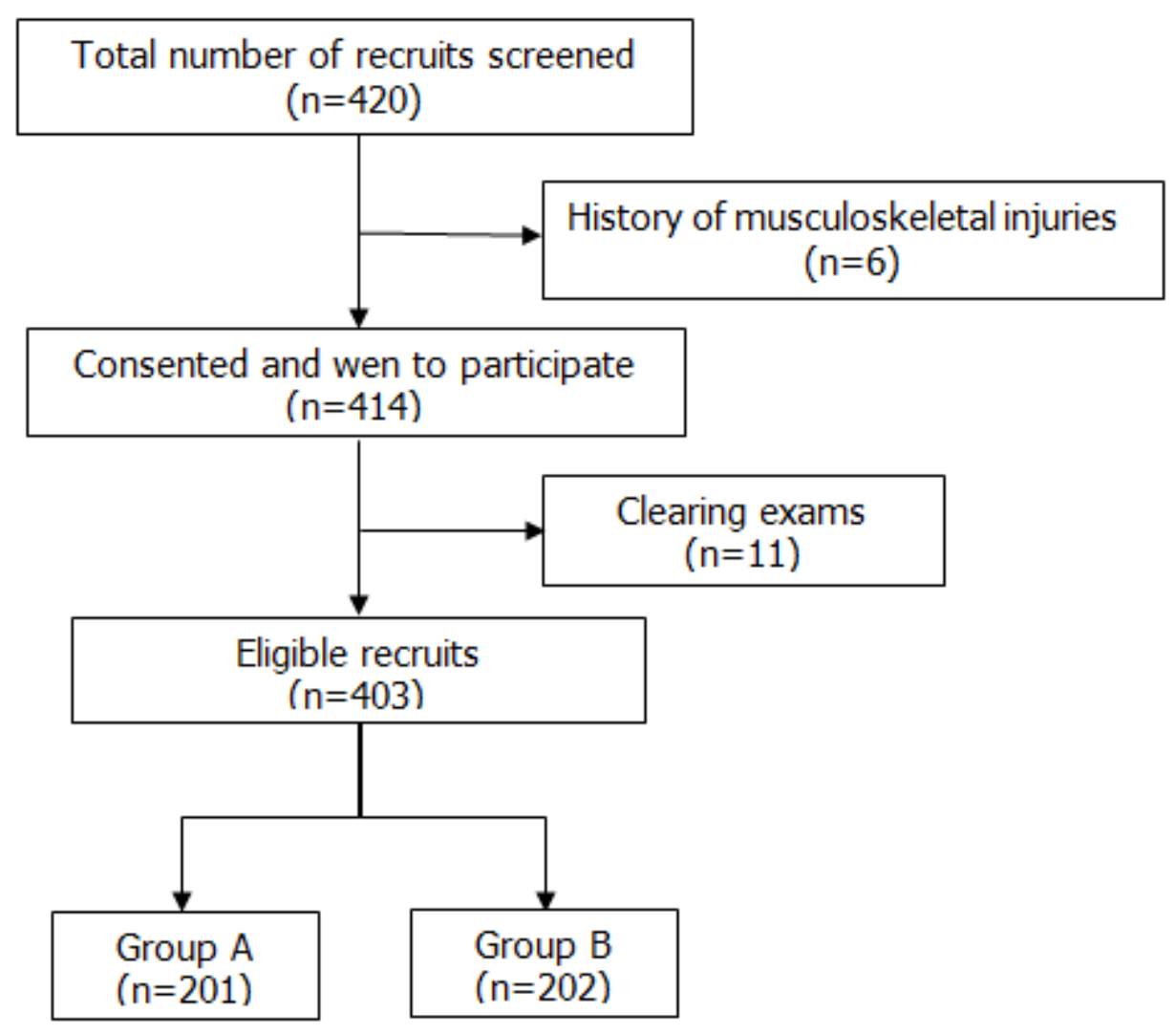

Figure 1

Flow diagram of the recruits showing the study design 